\title{
Design and parametric characterization of flexure bearing as automotive valve spring replacement
}

\author{
M. Razali Hanipah ${ }^{1,2}$, Shahin Mansor ${ }^{1}$, M.R.M Akramin ${ }^{3}$ and Akhtar Razul Razali ${ }^{1,4}$ \\ ${ }^{1}$ Automotive Engineering Research Group (AERG), Faculty of Mechanical Engineering, \\ Universiti Malaysia Pahang, 26600 Pekan, Pahang, Malaysia \\ "Email: mohdrazali@ump.edu.my \\ ${ }^{2}$ Automotive Engineering Centre (AEC), Universiti Malaysia Pahang, \\ 26600 Pekan, Pahang, Malaysia \\ ${ }^{3}$ Structural Materials and Degradation Group (SMDG), \\ Faculty of Mechanical Engineering, Universiti Malaysia Pahang, \\ ${ }^{4}$ Manufacturing Focus Group (MFG), Faculty of Mechanical Engineering, \\ Universiti Malaysia Pahang,
}

\begin{abstract}
Automotive valve springs occupy substantial space in the cylinder head of an internal combustion engine and contribute to frictional loss. In this paper, the design and analyses of a flat spring concept, known as flexure bearing are presented. Flexure bearing act like a typical spring which support the shaft but only allow axial displacement, thus reduce the friction of the system. The objective of the research is to design and conduct parametric characterization of flexure bearing for valve spring replacement in a small internal combustion engine. The analyses of flexure bearing strength for different designs, materials and thicknesses were conducted using finite element method. The results show that the maximum stress values are less affected by the material type compared to the number of arms despite a significant difference in young modulus values. The strain values are limited to less than $1 \%$ for all materials when the thickness is more than $1 \mathrm{~mm}$. The results have provided characteristics for future selection of the flexure bearing in relation to the intended axial displacement.
\end{abstract}

Keywords: Flexure Bearing; Finite Element; Design

\section{INTRODUCTION}

A recent successful trend in passenger vehicles improvement involved fuel economy improvement through start-stop technology [1,2]. An aggressive approach to reduce fuel consumptions is by improving internal combustion engine efficiency. Valvetrain components design are essential towards an efficient internal combustion engine. One of the component is valve springs, whose stiffness, dimensions and mass are critical for engine operation $[3$, 4]. In addition, poorly designed valve springs could cause abnormal vibration and hence, noise [5]. Flexure bearing is metal disc with slots cutting that permit flexing in the axial direction while ensuring a higher radial stiffness. Mostly, flexure bearing is used to support 
shafts that perform a purely linear motion and are commonly used in free piston Stirling machine incorporated with a linear motor [6]. Gaunekar, Göddenhenrich [7] presented nondimensional design curves for a flexure disc with spiral arm configuration for a certain range of sizes and strokes obtained from finite element analysis and validated through experimental measurements. Chen, Chen [8] had presented a spiral profile design procedures and parameter analyses through finite element analyses. Lee and Pan [9] had presented flexure bearing analysis procedures and design charts. According to the design charts developed for the spiral flexure, material fatigue stress allowable and the flexure stiffness requirement were chosen as a preferred design configuration [9]. Simcock [10] had presented investigation of materials for long life, high reliability flexure bearing springs for Stirling cryocooler applications. Kavade and Patil [6] had investigated the flexure bearing in linear compressor by varying the spiral angle with result through finite element method. Jomde, Anderson [11] had conducted parametric investigation on flexure bearing to enhance its performance and service life. Thombare and Dhande [12] conducted parametric modelling and FEA analyses for flexural bearings with different spiral profiles but limited to $1 \mathrm{~mm}$ thickness.

In this paper, the design characteristics of flexure bearing for replacing an existing single cylinder engine valve spring are investigated through finite element analyses. It covers different types of materials, designs and thicknesses.

\section{METHODOLOGY}

\section{Geometric Characteristic}

Geometrical characteristic is one of the most importance design characteristics of a flexure bearing as it can influence the performance and frequency. The typical design is a circular plate with three Archimedes spiral slits [13], this slit is known as involute and mathematically presented in details by Chen, Chen [8].

A variation of geometry parameters should be considered when designing a flexure spring; such as the thickness of the disk, the number of arms, the turn angle, the diameter of starting and ending hole, the slot width, arm width and a fixed radius at the beginning of the spiral [8].

Each spiral slot is made of locus of points corresponding to the location over time of a point moving away from a fix centre point with a constant speed along a line which rotates with constant angular velocity. Equivalently, in polar coordinates $(r, \theta)$ the equation can describe as

$$
r=a+b \theta
$$

with real numbers $a$ and $b$. Changing the parameter $a$ will turn the spiral, while $b$ controls the distance between successive turnings. The parametric Cartesian equation in Cartesian coordinate is defined respectively as:

$$
\begin{aligned}
& x=\cos (\theta)+\theta \sin (\theta) \\
& y=\sin (\theta)-\theta \cos (\theta)
\end{aligned}
$$


Figure 1 shows the geometric representation of involute in two-slot design developed in computer aided design (CAD) tool.

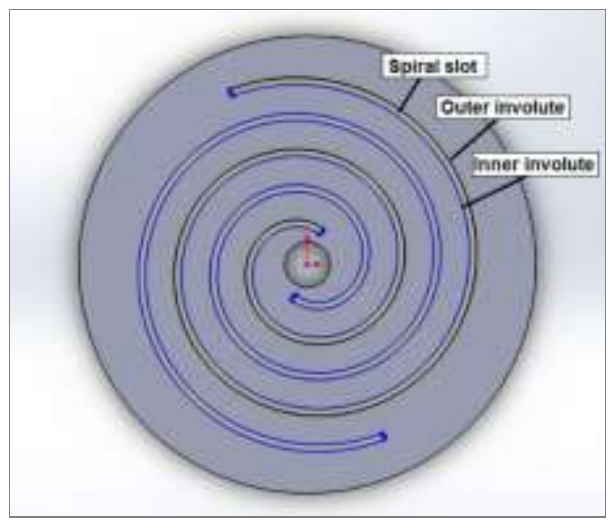

Figure 1. Geometrical description of involute

\section{Target Specifications}

The replacement spring is for a small internal combustion engine with $65 \mathrm{cc}$ cylinder capacity, four-stroke cycle run on gasoline [14]. It is chosen due to its small and compact size, simple design, air-cooled, mass-produced and availability of spare parts. Further, it runs on a fourstroke cycle engine utilising two-stroke lubrication and intake crankcase compression. Table 1 shows the engine specifications as obtained from the manufacturer datasheet and from measurement in the lab setup as outlined in [15].

Table 1. The engine specifications.

\begin{tabular}{lc}
\hline \multicolumn{1}{c}{ Parameter } & Value \\
\hline Capacity $\left[\mathrm{cm}^{3}\right.$ ] & 65 \\
Bore [mm] & 50 \\
Stroke [mm] & 33 \\
Geometric compression ratio [-] & $9.5: 1$ \\
Valve lift [mm] & 4.0 \\
Intake valve diameter [mm] & 20 \\
Exhaust valve diameter [mm] & 18 \\
\hline
\end{tabular}


Figure 2 shows the current valve spring configuration of the engine where a set of spring retainer plate holds each helical spring in pre-compression state to keep both valves closed. The opening and closing of the valve during engine cycle is done through cam actuated mechanism which is beyond the scope of this paper.

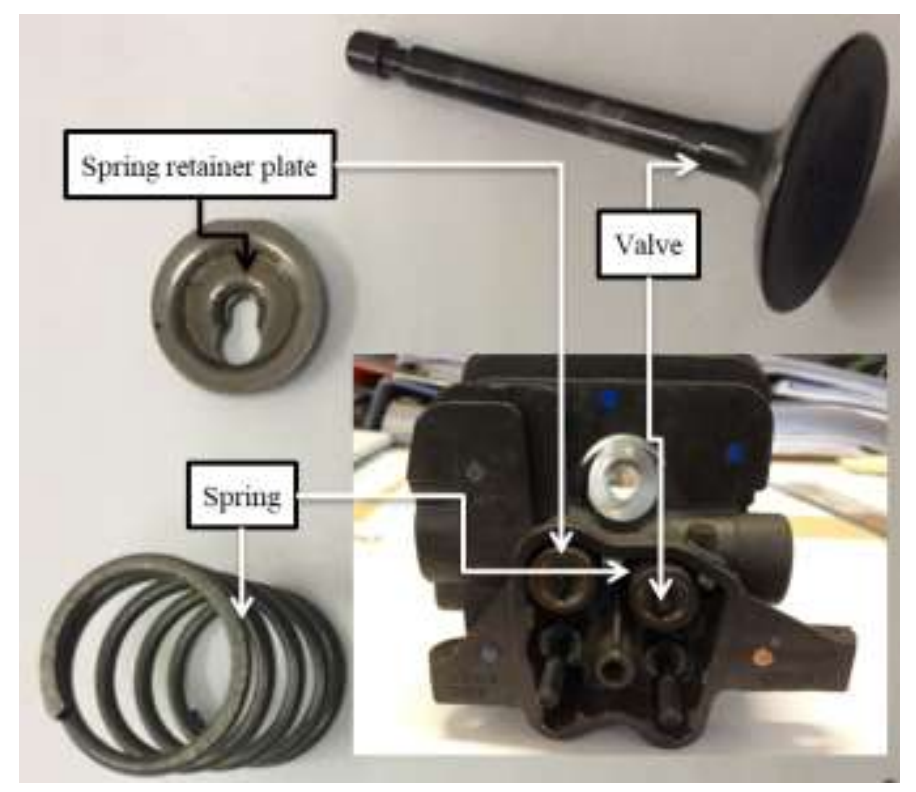

Figure 2. The current valve-spring configuration on the engine.

\section{Design and Finite Element Analyses}

Upon employing the design procedures for flexure bearing, several conceptual designs are constructed using three-dimensional computer aided design (CAD) tool.

There are three concepts of created in 3D CAD for the project as shown in Figure 3. The concept selection process depends on the several aspects evaluated through a design matrix. Among important design aspects are the material characteristics and design strength. The third concept has been chosen based on its simplicity, low cost of manufacturing with potentially lowest mechanical stress as reported by Jomde, Anderson [11] and Kharadi, Jadhav [16]. 


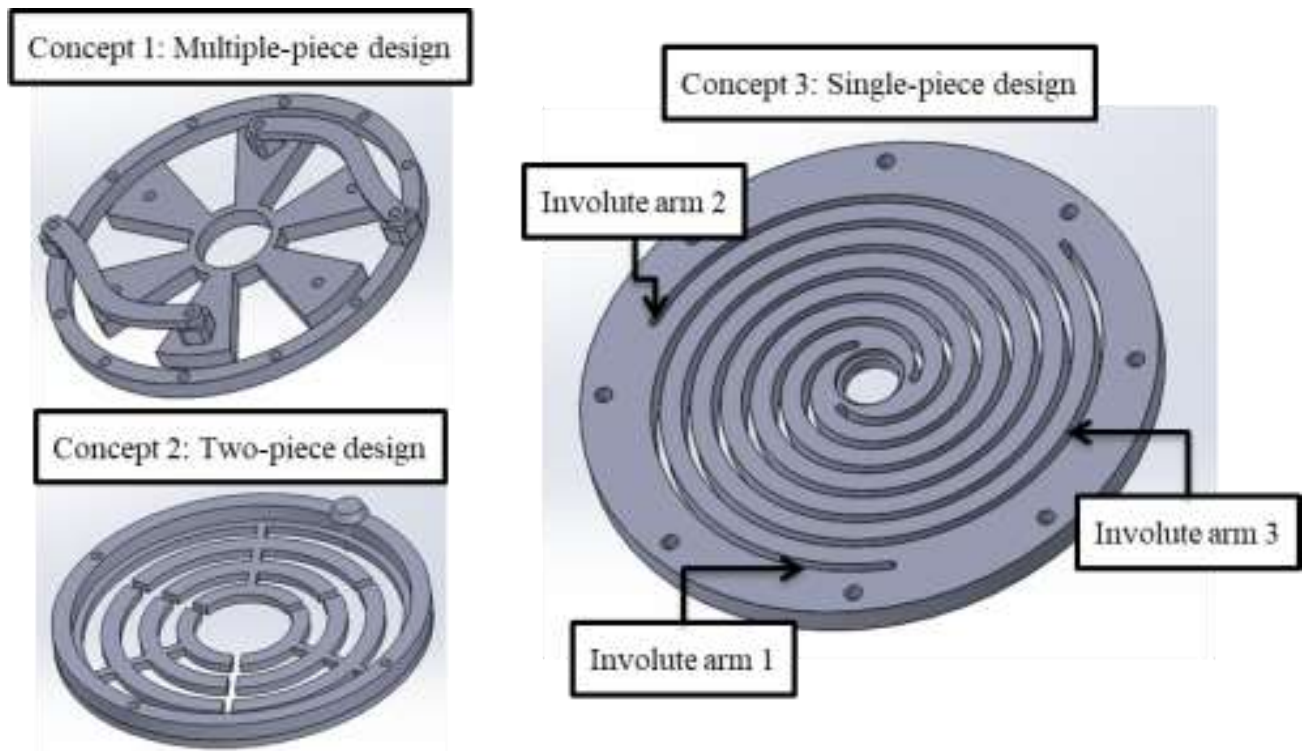

Figure 3. Three flexure bearing concept designs developed in 3D CAD.

Further analyses of the flexure bearing strength and elasticity was conducted using SolidWorks Simulation under mechanical testing. The simulation tool is general purpose finite element analysis which is reliable for linear elastic analysis [17].

This study focus on three major aspects of analysing the flexure bearing design which are the thickness, number of arm and material type. These parameters are important for better understanding of the flexure bearing characteristics for replacing the conventional valve spring. Next, the material of the design is selected. Choosing different material will affect greatly on the result of analysis due to material properties. Steel alloy is first selected for the flexure bearing. Other materials chosen includes stainless steel, beryllium copper alloy and titanium alloy based on previous research [18].

Figure 4 summarised the FEA procedures in SolidWorks simulation. First the design is fixed, then it is loaded with $20 \mathrm{~N}$ force which is similar to the maximum force generated on the helical spring of current engine at maximum lift. Finally, meshing is applied with appropriately chosen number of nodes and mesh size. 

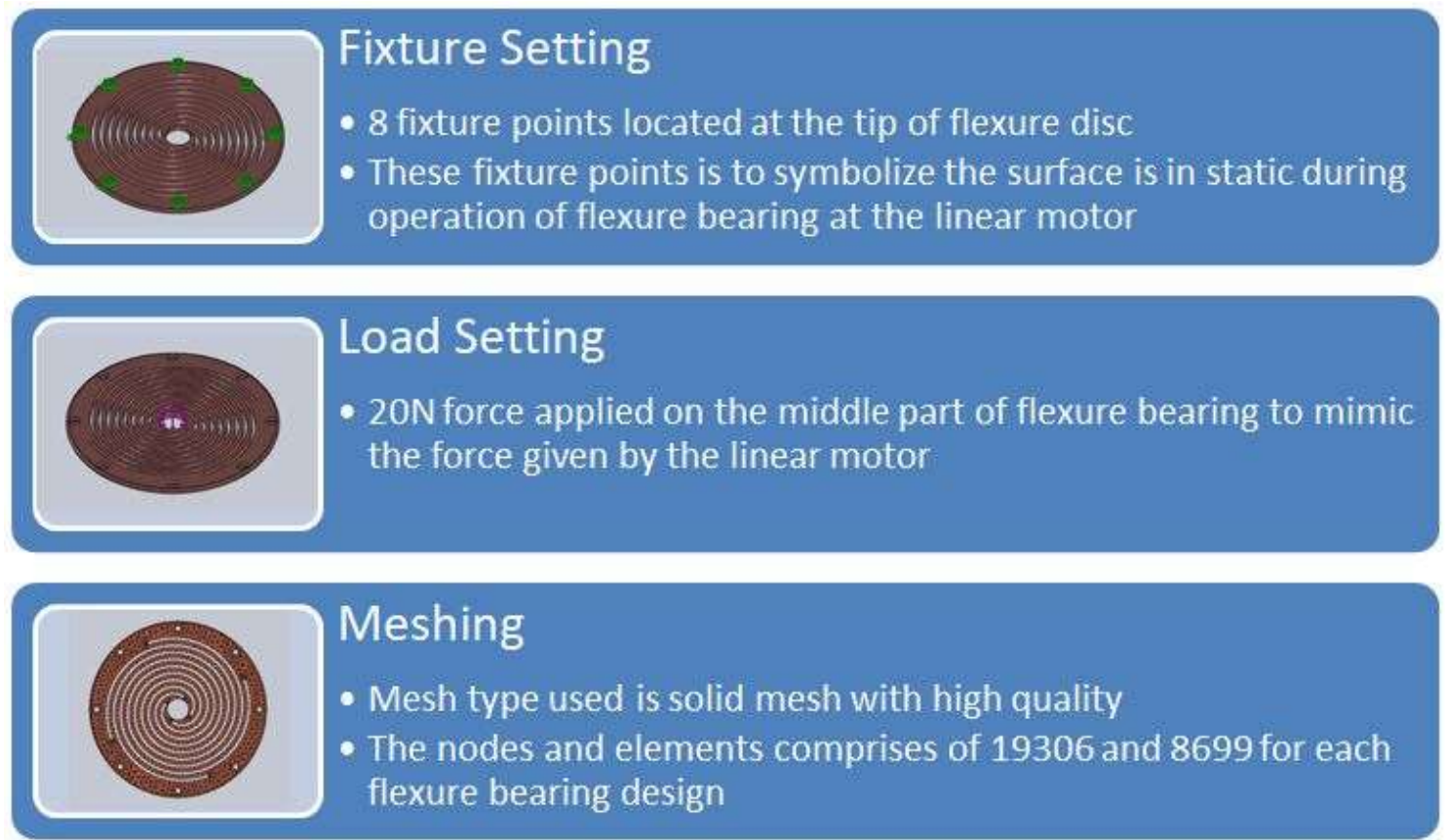

Figure 4. The fixture, load settings and meshing for the finite element analyses in SolidWorks.

Table 2 shows the governing design parameters for the parametric design simulation. The number of arms, thickness and material have been identified as the main parameters affecting the design of the flexure bearing.

Table 2. The details of design parameters for flexure bearing simulation.

\begin{tabular}{cc}
\hline Parameters & Value / Input \\
\hline \multirow{3}{*}{ Number of arms } & 2 \\
& 3 \\
& 4 \\
Thickness [mm] & 5 \\
& 0.5 \\
& 1.0 \\
Material & 1.5 \\
& 2.0 \\
& Ti-6 \\
& BeCu C13700 \\
& Alloy Steel AISI 4160 \\
\hline
\end{tabular}




\section{RESULTS AND DISCUSSIONS}

The static analyses focused on axial displacement, stress analyses and strain analyses. From these analyses, different parameters such as thickness, type of material and number of arms were analysed using FEA method under SolidWork simulation.

\section{Axial Displacement}

Figure 5 illustrate the FEA model axial displacement, in this case it shows the maximum displacement of the centre up to $20 \mathrm{~mm}$ under the $20 \mathrm{~N}$ load.

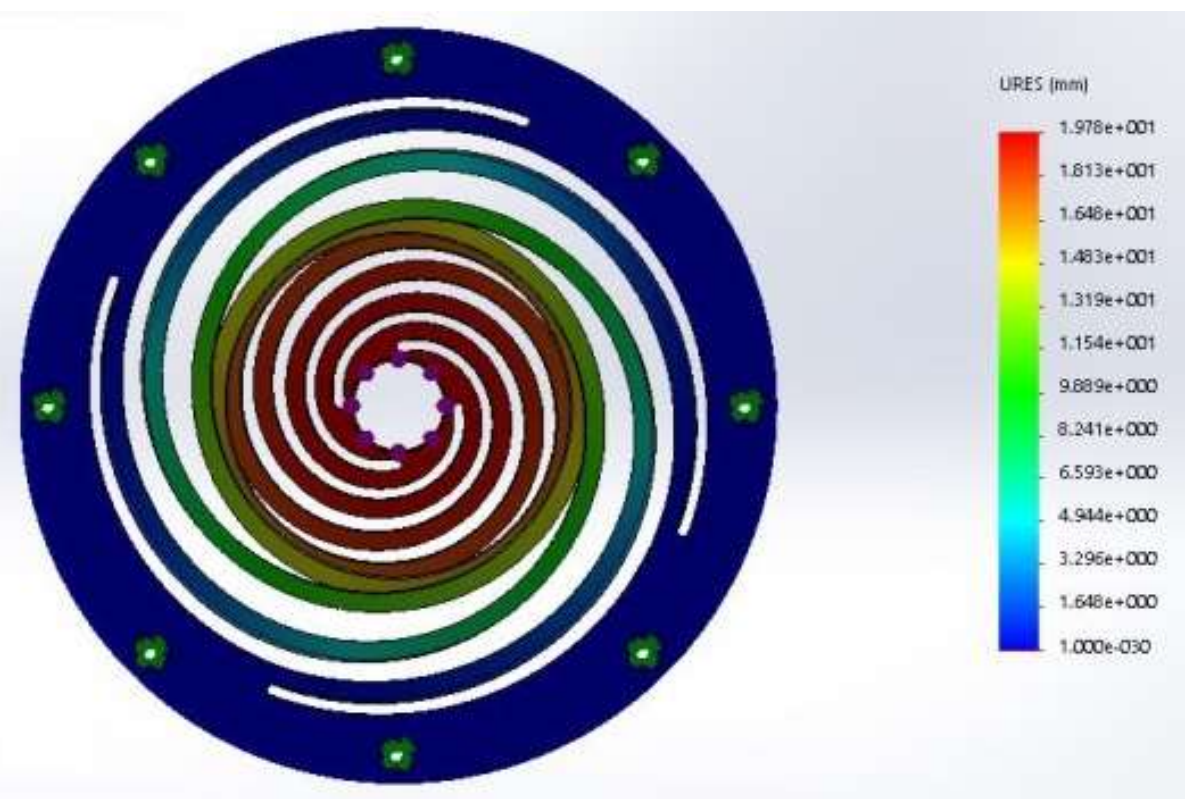

Figure 5. Deformation of flexure bearing model.

By changing the design parameters and materials, subsequent models were analysed. Figure 6 shows flexure bearing for steel alloy where the axial displacement rose steeply when the number of arms is more than 3 while the thickness is $0.5 \mathrm{~mm}$. A steady rise can be observed for other thicknesses. 


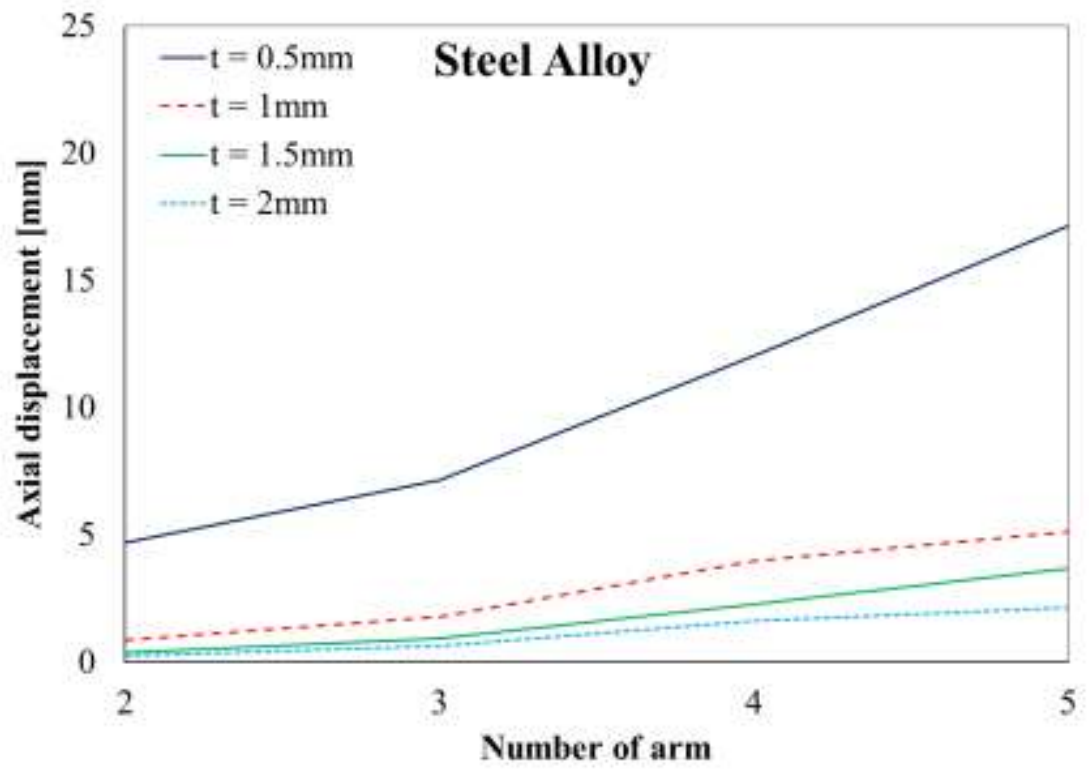

Figure 6. The maximum axial displacement at $20 \mathrm{~N}$ for various thicknesses and arm quantity of steel alloy.

Different trend is observed in stainless steel, beryllium copper and titanium alloy as shown in Figure 7 until Figure 9. Apparently in all these materials, the flexure bearing becomes rigid when the number of arm is more than 4 .

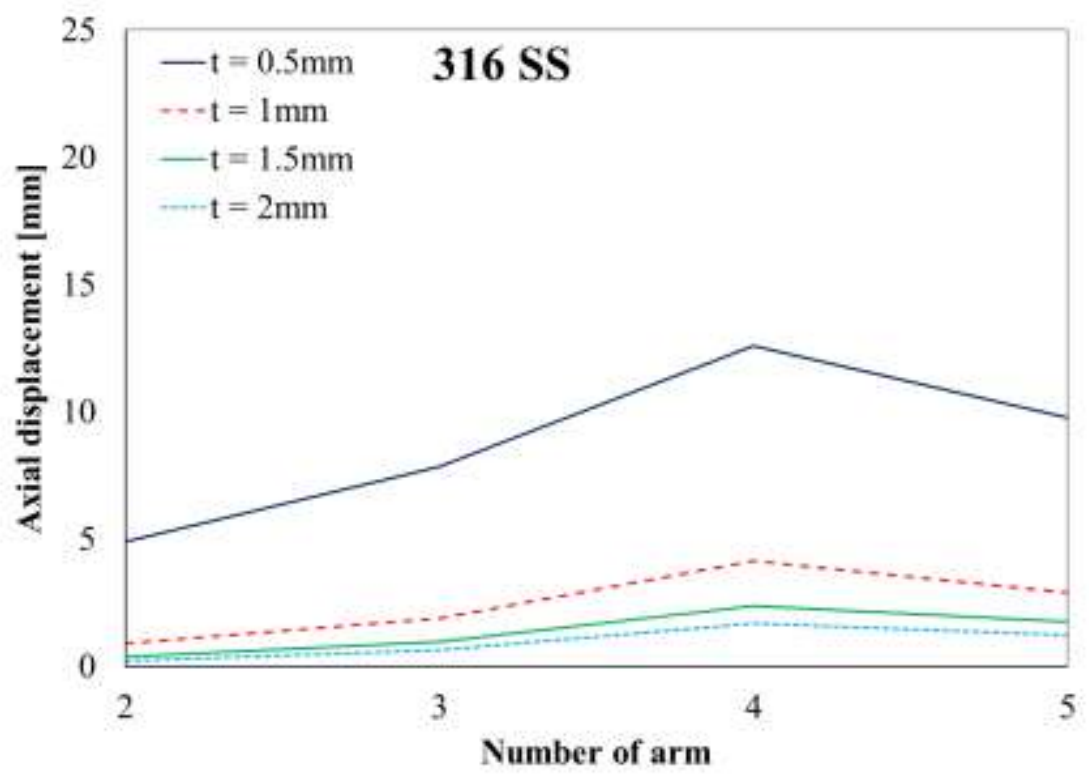

Figure 7. The maximum axial displacement at $20 \mathrm{~N}$ for various thicknesses and arm quantity of stainless steel (316 SS). 


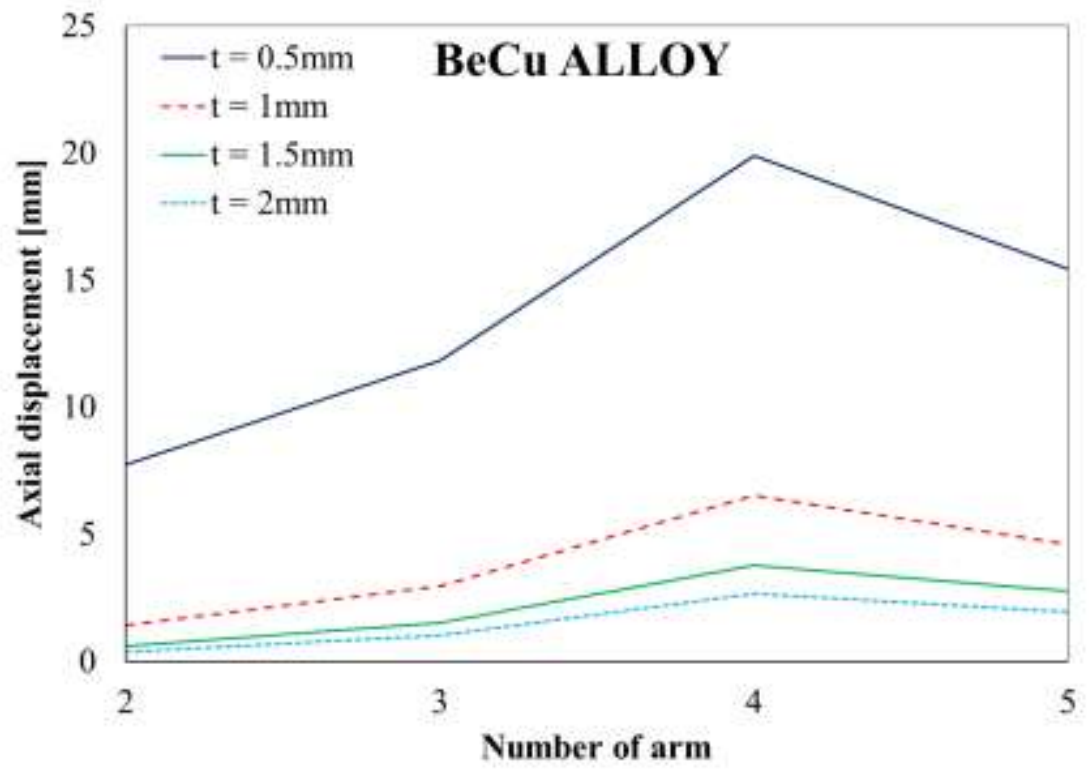

Figure 8. The maximum axial displacement at $20 \mathrm{~N}$ for various thicknesses and arm quantity of beryllium copper $(\mathrm{BeCu})$ alloy.

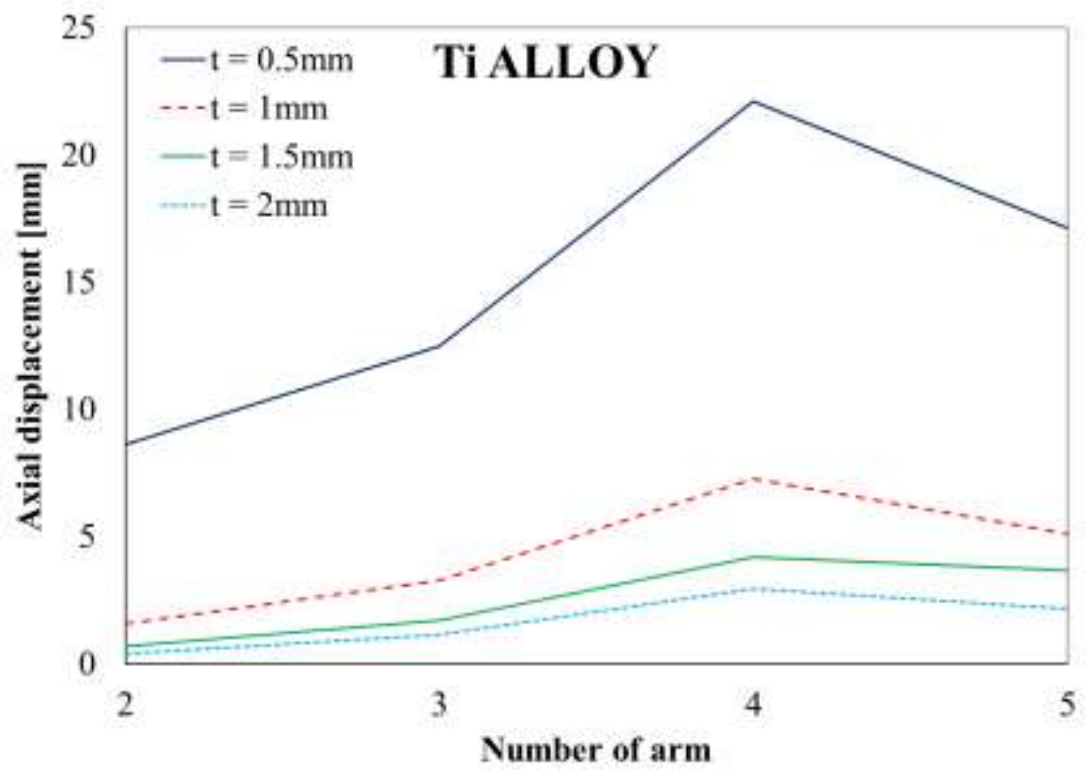

Figure 9. The maximum axial displacement at $20 \mathrm{~N}$ for various thicknesses and arm quantity of titanium alloy.

Based on these different materials modelled, the results show higher axial displacement for titanium alloy compared to other material. This is related to modulus of elasticity of the material. Titanium has the highest axial displacement due to lowest value of elastic modulus at $115 \mathrm{MPa}$ compared to steel alloy at $210 \mathrm{MPa}$. 
In terms of the number of arms, the results show that by increasing the number of arms resulted in higher axial displacement due to lower axial stiffness [6]. However, this research has found that at 5-arm design, the axial displacement obtained shows a decline. Figure 10 illustrates the impact of number of arms with axial displacement values.

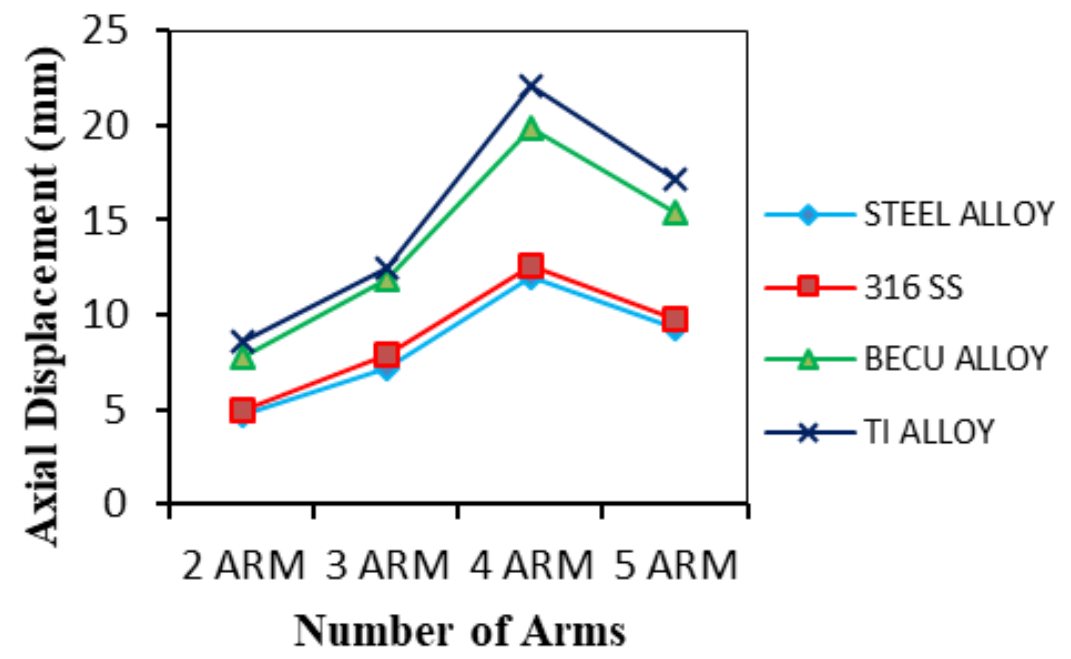

Figure 10. Axial displacement vs. number of arms of different materials for $0.5 \mathrm{~mm}$ thickness of flexure bearing.

\section{Stress Analysis}

Figure 11 shows the distribution of equivalent stress of flexure bearing for 4-arm design when the $20 \mathrm{~N}$ load was exerted on the centre part.

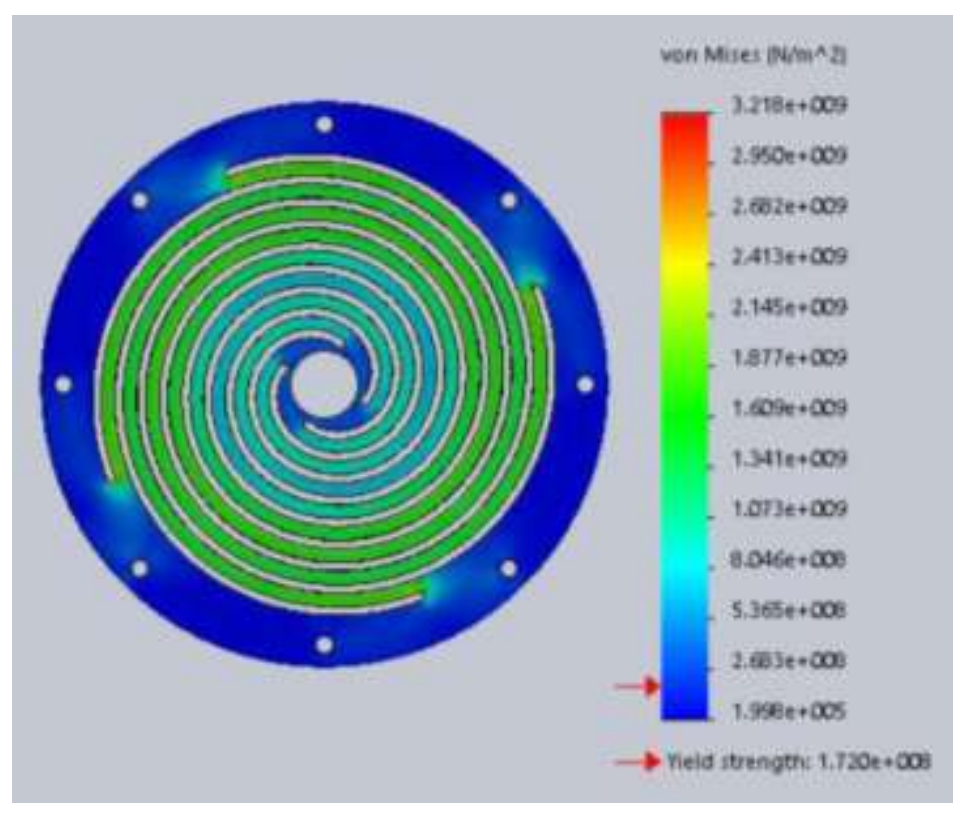

Figure 11. Stress analysis of flexure bearing model. 
The results obtained from the simulation shows that most of the maximum stress occurred at the end of the involute as shown in Figure 12 and the lowest at the fixture points. This maximum stress can be reduced as proposed by Meymian, Clark [19], up to 20\% of stress reduction can be achieved when applying a semi-circle end profile on end point of spiral [19].

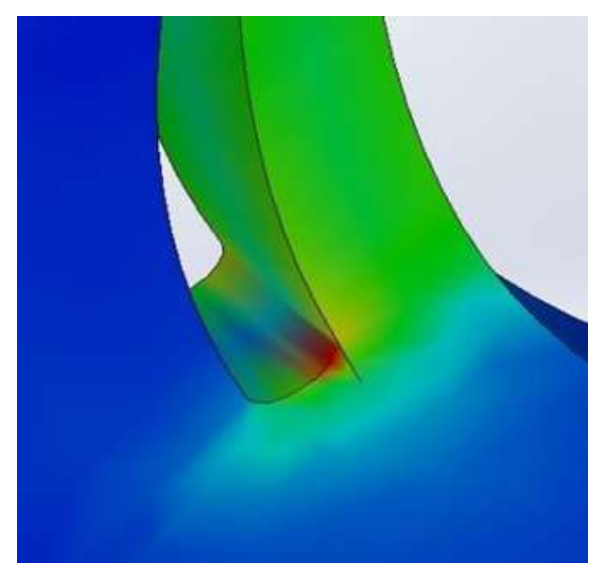

Figure 12. Maximum stress concentration

Figure 13 shows the stress versus number of arms for different materials at $0.5 \mathrm{~mm}$ thickness of flexure bearing design. It shows that the value of stress increasing when the number of arm increase. Further, at 4 and 5 arms design; the maximum stress is almost similar for all materials. Based on the result obtained, five-arm flexure produces the highest value of von Mises stress with titanium alloy produce $4.2 \mathrm{GN} / \mathrm{m}^{2}$.

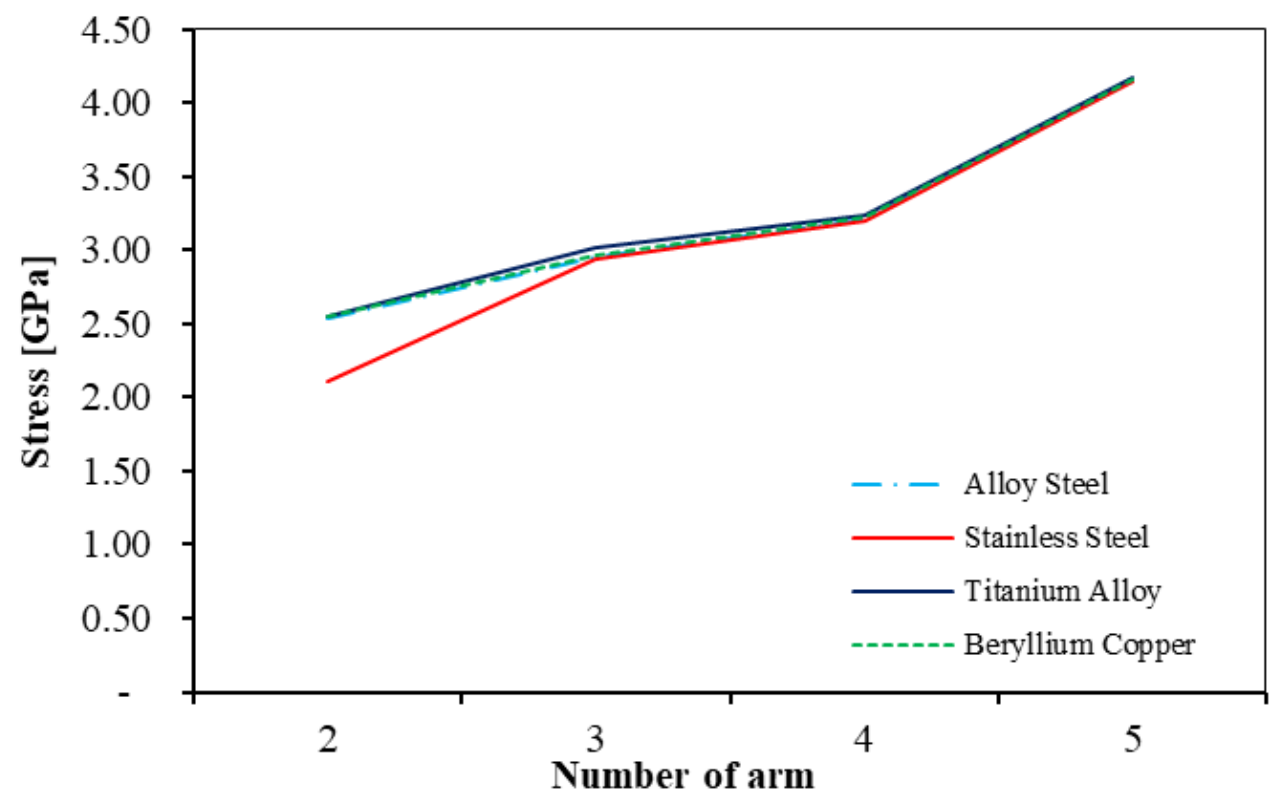

Figure 13. Stress vs. number of arms in different materials for $0.5 \mathrm{~mm}$ thickness of flexure bearing. 


\section{Strain Analyses}

Figure 14 shows the strain contour of 4-arm flexure bearing under the same loading which correlates to the stress contour shown in Figure 11.

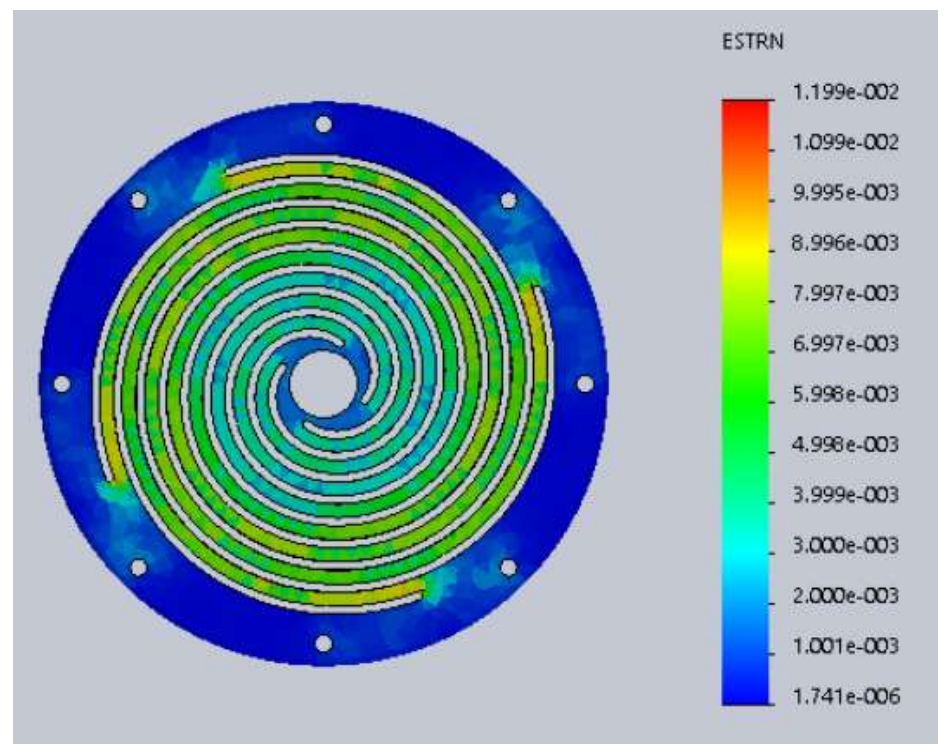

Figure 14. Strain analysis of flexure bearing model.

Figure 15 shows the maximum strain values of 4-arm design in different materials. The highest strain was produced in $0.5 \mathrm{~mm}$ thickness design for the titanium alloy with a value of $7.24 \mathrm{E}-03 \mathrm{~mm} / \mathrm{mm}$. The strain decreases along with the thickness of flexure bearing.

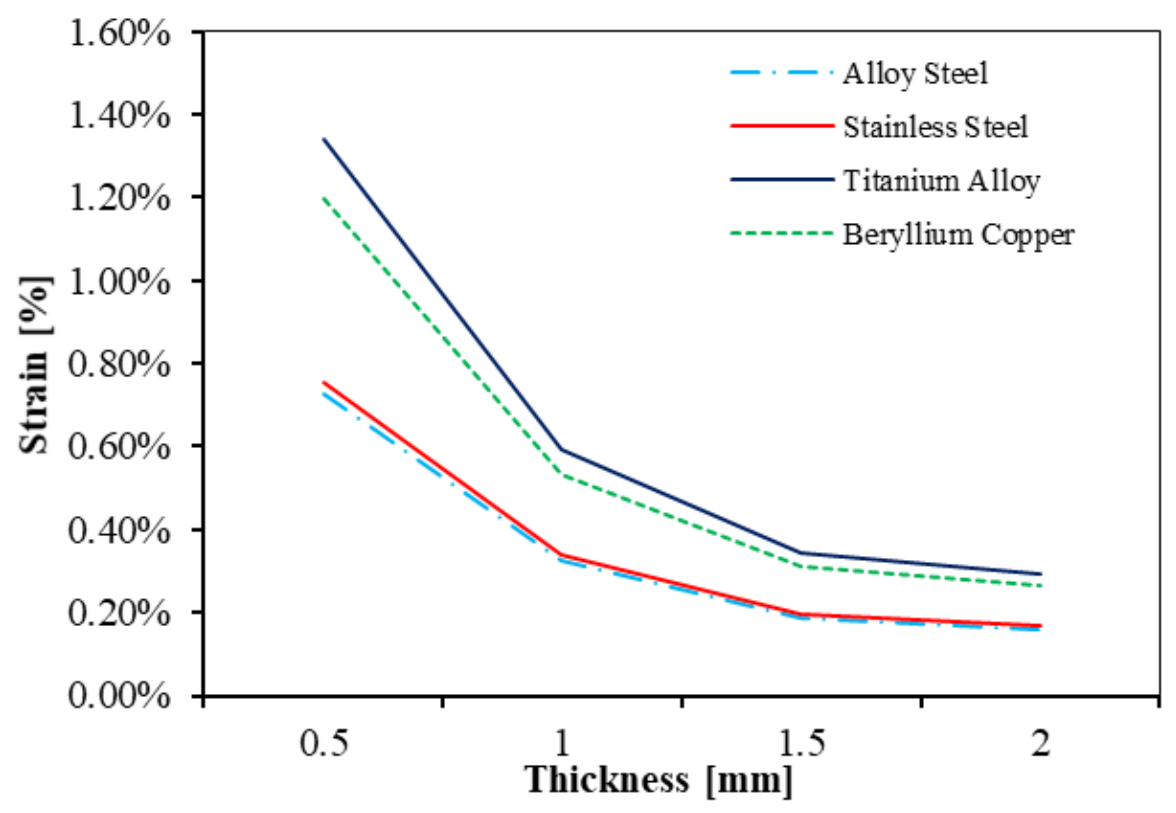

Figure 15. Strain vs. thickness in different material of 4 arms flexure. 


\section{CONCLUSIONS}

In this investigation, the aim was to design and conduct parametric characterization of flexure bearing. Three concept designs were developed, and a final single piece design was selected due to its simple and cost-effective design.

This single piece design has undergone parametric investigations using finite element method in three-dimensional model. The effect of different thicknesses, types of materials and number of arms were studied.

It is found that, Titanium alloy produced the highest axial displacement at $23 \mathrm{~mm}$ when subjected to the same load value as compared to other materials tested. This has resulted in the highest maximum stress for Titanium alloy at $4.2 \mathrm{GN} / \mathrm{m}^{2}$. However, the maximum stresses in all materials approaches similar values when the number of arm is more than three up until five arms (which is the maximum quantity in the design). Finally, the strain values for all materials are less than $1 \%$ when the thickness is above $1 \mathrm{~mm}$.

\section{ACKNOWLEDGEMENTS}

The authors would like to thank the Ministry of Energy, Science, Technology, Environment and Climate Change (MESTECC) for the financial grant (project no. 03-01-16-SF0172) and also Universiti Malaysia Pahang (www.ump.edu.my) for providing laboratory facilities.

\section{REFERENCES}

[1] Abas MA, Wan Salim WS, Ismail MI, Rajoo S, Martinez-Botas R. Fuel consumption evaluation of SI engine using start-stop technology. Journal of Mechanical Engineering and Sciences 2017;11:2967-78.

[2] Salim WSIW, Mahdi AAM, Ismail MI, Abas MA, Martinez-Botas RF, Rajoo S. Benefits of spark-ignition engine fuel-saving technologies under transient part load operations. Journal of Mechanical Engineering and Sciences 2017;11:3027-37.

[3] Siczek K, Siczek K. Studies on the dynamics the valve train with machined valve springs. Combustion Engines 2017;1.

[4] Gowtham R, Sangeetha N. Design and analysis of exhaust valve springs in IC engines. International Journal of Innovative Research in Science, Engineering and Technology 2017.

[5] Zheng H, Yan F, Lu C, Xu F, Li Q, Tian W. Optimization design of the valve spring for abnormal noise control in a single-cylinder gasoline engine. Proceedings of the Institution of Mechanical Engineers, Part D: Journal of Automobile Engineering 2017;231:204-13.

[6] Kavade MV, Patil CB. Optimization of Flexure Bearing Using FEA for Linear Compressor. International Journal of Engineering and Science 2012.

[7] Gaunekar AS, Göddenhenrich T, Heiden C. Finite element analysis and testing of flexure bearing elements. Cryogenics 1996;36:359-64.

[8] Chen N, Chen X, Wu YN, Yang CG, Xu L. Spiral profile design and parameter analysis of flexure spring. Cryogenics 2006;46:409-19. 
[9] Lee CC, Pan RB. Flexure Bearing Analysis Procedures and Design Charts. In: R.G. R, editor. Cryocoolers 9. Boston, MA: Springer; 1997.

[10] Simcock CJ. Investigation of Materials for Long Life, High Reliability Flexure Bearing Springs for Stirling Cryocooler Applications. In: International Cryocooler Conference, 2007.

[11] Jomde A, Anderson A, Bhojwani V, Kharadi F, Deshmukh S. Parametric Analysis Of Flexure Bearing For Linear Compressor. Materials Today: Proceedings 2017;4:2478-86.

[12] Thombare AT, Dhande DY. Modeling and FEA analysis of Flexural Bearing for Different Profiles. International Journal of Engineering Trends and Technology 2015;20:175-8.

[13] Al-Otaibi ZS, Jack AG. Spiral flexure springs in single phase linear-resonant motors. In: 42nd International Universities Power Engineering Conference, Brighton, UK, 46 September, 2007.

[14] Andreas Stihl AG. 4-MIX engine: Lightweight and with good lugging power. Retrieved from http://www.stihl.com/4-mix-engine-lightweight-and-with-goodlugging-power.aspx; 17 November 2014.

[15] Zahidi MK, Hanipah MR, Ramasamy D, Noor MM, Kadirgama K, Rahman MM. The two-stroke poppet valve engine. Part 1: Intake and exhaust ports flow experimental assessments. IOP Conference Series: Materials Science and Engineering 2017;257:012023.

[16] Kharadi FH, Jadhav MS, Kanhurkar SD, Pereira PA, Bhojwani VK, Phadkule S. Selection Of High Performing Geometry In Flexure Bearings For Linear Compressor Applications Using FEA. International Journal of Scientific \& Technology Research. 2015.

[17] Boyles C. Solid Solution: So how accurate is SOLIDWORKS Simulation? . Retrieved from https://www.solidsolutions.co.uk/blog/2017/09/so-how-accurate-isSOLIDWORKS-simulation/; 21 April 2018.

[18] Amoedo S, Thebaud E, Gschwendtner M, White D. Novel parameter-based flexure bearing design method. Cryogenics 2016;76:1-9.

[19] Meymian NZ, Clark NN, Musho T, Darzi M, Johnson D, Famouri P. An optimization method for flexural bearing design for high-stroke high-frequency applications. Cryogenics 2018;95:82-94. 